\title{
Reduction of Circulating Current Flow in Parallel Operation of APF Based on Hysteresis Current Control
}

\author{
Shafiuzzaman K. Khadem \\ Technological University Dublin \\ Malabika Basu \\ Technological University Dublin, mbasu@tudublin.ie \\ Michael Conlon \\ Technological University Dublin, michael.conlon@tudublin.ie
}

Follow this and additional works at: https://arrow.tudublin.ie/engscheleart

Part of the Electrical and Electronics Commons

\section{Recommended Citation}

Khadem, S.K.; Basu, M.; Conlon, M.F., "Reduction of circulating current flow in parallel operation of APF based on hysteresis current control," Power Engineering Conference (UPEC), 2013 48th International Universities' , vol., no., pp.1,6, 2-5 Sept. 2013 doi: 10.1109/UPEC.2013.6715013

This Conference Paper is brought to you for free and open access by the School of Electrical and Electronic Engineering at ARROW@TU Dublin. It has been accepted for inclusion in Conference papers by an authorized administrator of ARROW@TU Dublin. For more information, please contact arrow.admin@tudublin.ie, aisling.coyne@tudublin.ie,gerard.connolly@tudublin.ie.

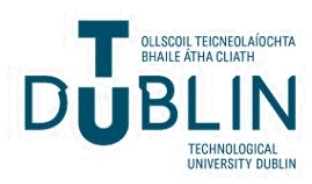




\section{Reduction of circulating current flow in parallel operation of APF based on hysteresis current control}

\author{
Shafiuzzaman K Khadem \\ Member IEEE \\ School of Electrical \& \\ Electronic Engineering, Dublin \\ Institute of Technology, Ireland \\ E-mail: skkhadem@gmail.com
}

\author{
Malabika Basu \\ Member IEEE \\ School of Electrical \& Electronic \\ Engineering, Dublin Institute of \\ Technology, Ireland \\ E-mail: malabika.basu@dit.ie
}

\author{
Michael F Conlon \\ Member IEEE \\ School of Electrical \& \\ Electronic Engineering, Dublin \\ Institute of Technology, Ireland \\ E-mail: michael.conlon@dit.ie
}

\begin{abstract}
Capacity enhancement and operation flexibility are two of the important limitations of the centralized Shunt Active Power Filter $\left(\mathbf{A P F}_{\text {sh }}\right)$ unit. This can be overcome by multiple and parallel $\mathrm{APF}_{\mathrm{sh}}$ units (in distributed mode) with a common DC link. In that case, a circulating current (CC) can flow. In the case of a hysteresis current controller based multiple $\mathbf{A P F}_{\text {sh }}$ units in load sharing mode, this CC control is not yet achieved. One of the difficulties of this $\mathrm{CC}$ flow control or reduction is the variable switching frequency of the $\mathbf{A P F}_{\text {sh }}$ units. In this paper, the model for $\mathrm{CC}$ flow is derived by the switching dynamics study of the $\mathbf{A P F}_{\mathrm{sh}}$ units. Detailed simulation and real time study show that the reduction of $\mathrm{CC}$ flow can be achieved at an acceptable level by proper selection of design parameters.
\end{abstract}

Index Terms-- Active Power Filter, Power Quality, Zerosequence circulating current, hysteresis control, Capacity enhancement

\section{INTRODUCTION}

The power quality, at all time, is a matter of concern where a number of non-linear, harmonics producing and sophisticated loads are connected in a electrical distribution network. In that case $\mathrm{APF}_{\mathrm{sh}}$ is finding greater applications for power quality (PQ) improvement in the distributed network. In high power applications, the filtering task cannot be performed for the whole spectrum of harmonics by using a single converter due to the limitations on switching frequency and power rating of the semiconductor devices. Therefore, compensating the non-active components to improve the power quality of the distributed network as well as to avoid the large capacity centralised $\mathrm{APF}_{\mathrm{sh}}$, parallel operation of multiple low power $\mathrm{APF}_{\text {sh }}$ units are increasing. Different controlling mechanism and topologies are available in handling the difficulties of parallel operation of $\mathrm{APF}_{\text {sh }}$ either in active load sharing or distributed mode. A detailed technical review on parallel operation of $\mathrm{APF}_{\text {sh }}$ for current and voltage harmonic compensation in a distributed generation (DG) network have been done in $[1,2]$ where the pros and cons of the different control methods have been discussed. For these cases, there is no physical/electrical link between the $\mathrm{APF}_{\mathrm{sh}}$ units. The system components and cost can be reduced by maintaining a common DC link back-toback connection between the $\mathrm{APF}_{\mathrm{sh}}$ units [3]. But it then raises the control complexity by introducing the zerosequence circulating current (ZSCC) flow within the $\mathrm{APF}_{\text {sh }}$ units $[4,5]$.
Most of the control methods for the reduction of ZSCC discussed in the literature are mainly for PWM based multiple inverter or rectifier units [6-10]. Very few of the articles show the ZSCC reduction for the parallel operation of $\mathrm{APF}_{\text {sh }}$ units [11]. None of these discuss the ZSCC flow issues and control method for the parallel operation of Converter/APF $\mathrm{As}_{\mathrm{sh}}$ based on hysteresis control. Therefore, an attempt has been made here to discuss the issues related to hysteresis control.

\section{WORKING PRINCIPLE}

According to the working principle of an $\mathrm{APF}_{\mathrm{sh}}$ unit in parallel to the load to compensate the reactive and harmonic current, there are two possible modes of operation: capacitive mode (where the current flows from the capacitor) and inductive mode (the current flows towards the capacitor). When multiple APF units work in a current sharing mode, there could be four possible modes of operation: (i) capacitive-capacitive, (ii) inductive-inductive, (iii) capacitiveinductive and (iv) inductive-capacitive. As an example, Fig 1 shows a single line diagram of a 3 -phase system where $i_{c c}$ represents the circulating current flow between the APF units. In the case of a 3-phase system this circulating current flow exists as a zero sequence harmonics in the zero sequence current flow when a circulating loop is created within the $\mathrm{APF}_{\mathrm{sh}}$ units and hence it is termed zero sequence circualting current (ZSCC) flow. In general these harmonics are $(3+n * 6)$ order, where $\mathrm{n}=0,1,2$..

\section{MODEL FOR ZSCC FLOW}

For simplicity, derivation of ZSCC flow has been carried out on a per phase basis. Fig 2 shows the possible mode of operation between the $\mathrm{APF}_{\mathrm{sh}}$ units where $s h-i$ and $s h-c$ represent the inductive and capacitive mode respectively. If there is a difference in any of the parameters, such as switching frequency, interfacing inductor, hysteresis band (in hysteresis current controller) then the $\mathrm{APF}_{\text {sh }}$ units can operate in inductive-capacitive or capacitive-inductive mode. In these cases, ZSCC will flow and these are reflected in Fig 2 (f, h).

From Fig 2 ( $a$ and $b$ ), during the capacitive mode, the current flow can be obtained as;

$\frac{d i_{s h-c}}{d t}=\frac{v_{s h-c}-v_{p c c}}{L_{s h 1} \| L_{s h 2}}$ 


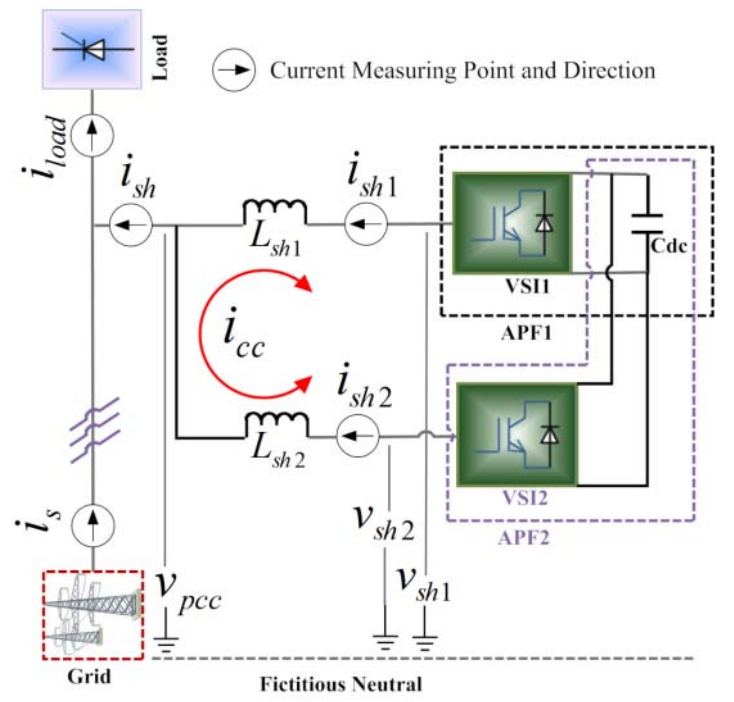

Fig 1: Single line diagram of a 3 ph 2 units $A_{P F}$ with common DC-link presenting $\mathrm{CC}$ flow

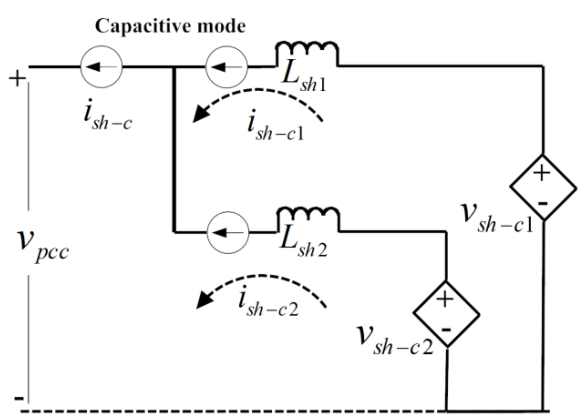

(a)

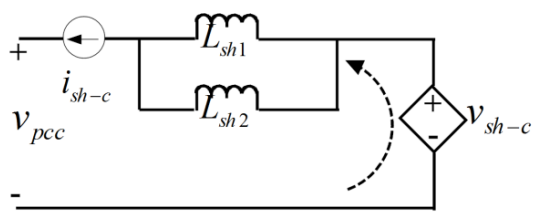

(b)

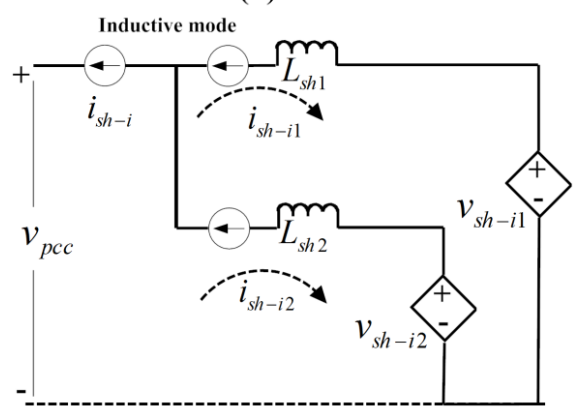

(c)

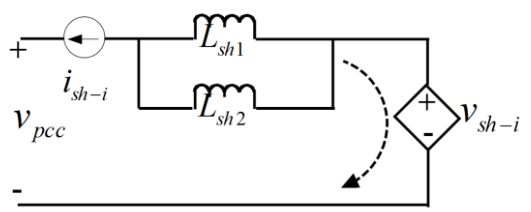

(d)

Fig 2: Possible mode of operation between two $\mathrm{APF}_{\mathrm{sh}}$ units to calculate circulating current while $v_{s h-c 1}=\delta_{1} v_{d c}=v_{s h-c 2}=\left(1-\delta_{2}\right) v_{d c}=v_{s h-c}$; here $\delta$ is the ducy cycle, i.e, the ac voltages of the $\mathrm{APF}_{\text {sh }}$ units are equal.

Similarly, Fig 2 (c and d) shows that when both the APF units work in inductive mode during its switching cycle, the resulting current flows can be found as;

$\frac{d i_{s h-i}}{d t}=-\frac{v_{s h-i}+v_{p c c}}{L_{s h 1} \| L_{s h 2}}$

while $v_{s h-i 1}=\left(1-\delta_{1}\right) v_{d c}=v_{s h-i 2}=\delta_{2} v_{d c}=v_{s h-i}$;

From Fig 2 (e and $\mathrm{f}$ ), the circulating current flow in capacitive-inductive mode can be obtained as;

$\frac{d i_{c c-c}}{d t}=\frac{v_{c c-c}}{L_{s h 1}+L_{s h 2}}=\frac{v_{s h-c 1}-v_{s h-i 2}}{L_{s h 1}+L_{s h 2}}=\frac{\left(\delta_{1}-\delta_{2}\right) v_{d c}}{L_{s h 1}+L_{s h 2}}$

while $v_{s h-c 1}>v_{s h-i 2}$

Similarly, the circulating current flow for inductivecapacitive mode is;

$\frac{d i_{c c-i}}{d t}=\frac{v_{c c-i}}{L_{s h 1}+L_{s h 2}}=\frac{v_{s h-i 1}-v_{s h-c 2}}{L_{s h 1}+L_{s h 2}}=-\frac{\left(\delta_{1}-\delta_{2}\right) v_{d c}}{L_{s h 1}+L_{s h 2}}$

while $v_{s h-i 1}>v_{s h-c 2}$

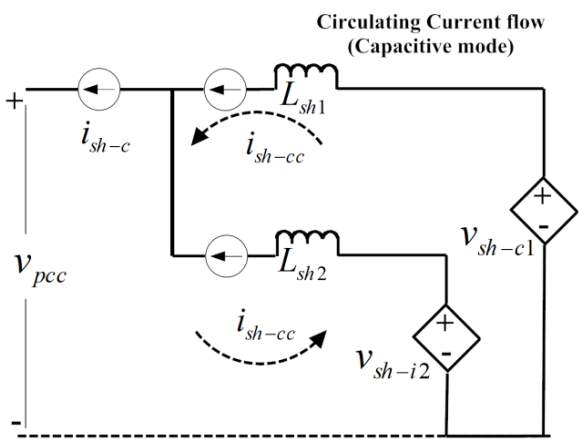

(e)

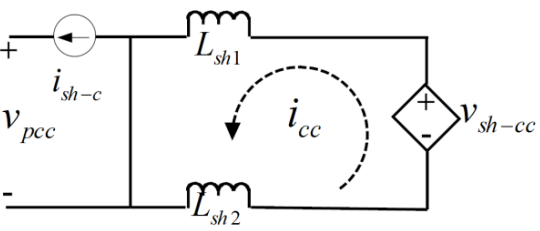

(f)

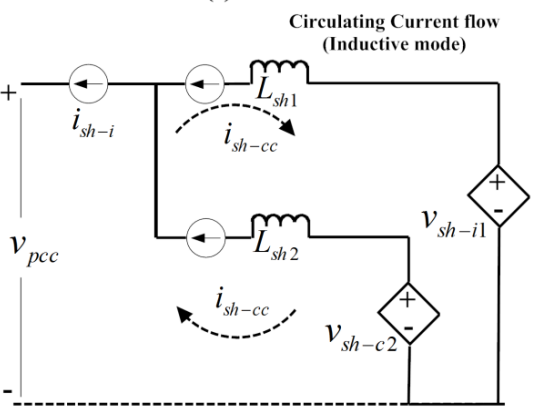

(g)

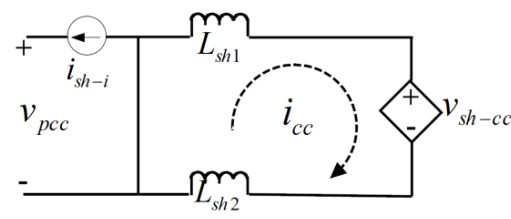

(h) 
Therefore, in general, the equation for the ZSCC flow can be written as;

$\frac{d i_{c c}}{d t}=\frac{\delta_{c c} v_{d c}}{L_{s h 1}+L_{s h 2}}$

where $\delta_{c c}=\delta_{1}-\delta_{2}$ for capacitive mode and $\delta_{c c}=\delta_{2}-\delta_{1}$ for inductive mode.

The possible maximum value for $\mathrm{CC}$ can be obtained as;

$I_{c c-\max }=\frac{V_{d c}}{L_{s h 1}+L_{s h 2}}$

For 3-phase system, the ZSCC can be found as;

$Z S C C=i_{s h 1-z s} \sim i_{s h 2-z s}$

where $i_{s h 1-z s}$ and $i_{s h 2-z s}$ are the zero sequence component of the $\mathrm{APF}_{\text {sh }}$ units.

This is also confirmed in [11] for $\mathrm{APF}_{\mathrm{sh}}$ topology analysis based on a parallel interleaved inverter. It is also similar to the rectifier analysis in [6]. In most of the research articles, derivation or ZSCC cancellation has been carried out for two inverters or $\mathrm{APF}_{\mathrm{sh}}$ units [7-11]. Moreover, the control methods discussed in the literature are mainly for PWM based control system. None of them discuss the CC flow issues for the parallel operation of APFs based on hysteresis control. Therefore, an attempt has been made here to discuss the issues related to hysteresis control.

\section{CONTROL ISSUES FOR THE ZSCC FLOW}

There are mainly two ways to eliminate or reduce the ZSCC flow: (i) breaking the route of CC flow by introducing physical devices such as an isolation transformer or common mode inductor or (ii) by proper control methods. From the derivation of ZSCC flow it is found that the $\mathrm{CC}$ value depends on (i) the duty cycle $(\delta)$ or switching frequency $\left(f_{s w}\right)$, DC link voltage $\left(V_{d c}\right)$ and the interfacing inductor $\left(L_{s h}\right)$ of the APF units. Therefore, some design consideration should be made to reduce the CC flow. The design options that can be implemented to reduce the $\mathrm{CC}$ flow are;

i. Decrease the $V_{d c}$ : According to the design criteria of single/3-phase $\mathrm{APF}_{\mathrm{sh}}$ system there is a minimum value of $V_{d c}$ that has to be maintained to compensate the reactive and harmonic current.

ii. As the $\delta=\frac{\tau}{T}=\tau f_{s w}$, reduce the $f_{s w}$ and decreasing the difference between the $f_{s w}$ or $\delta$ will reduce CC flow.

iii. Reduced $f_{s w}$ will further increase the $L_{s h}$ (in the case of hysteresis current control) and it will then in turn reduce the circulating current flow. But increased $L_{s h}$ will reduce the VAR rating of $\mathrm{APF}_{\text {sh }}$.

It is also clear from the derivation that the $\mathrm{CC}$ flow does not directly depend on the compensating current rating of the $\mathrm{APF}_{\text {sh }}$ units. Therefore, once the current or VAR rating of $\mathrm{APF}_{\text {sh }}$ is fixed, the design components $\left(f_{s w}\right.$ and $\left.L_{s h}\right)$ should be chosen in such a way so that the $L_{s h}$ is possibly high and the $f_{s w}$ difference between the $\mathrm{APF}_{\text {sh }}$ units are as low as possible. In that case, introducing the common mode inductor in the $\mathrm{APF}_{\mathrm{sh}}$ units can be a better choice. Implementation of a $\mathrm{CC}$ control method in the $\mathrm{APF}_{\text {sh }}$ control strategy will further reduce the $\mathrm{CC}$ flow. But it will then increase the control complexity.

\section{SELECTION Of CONTROL METHOD FOR APF $\mathrm{AH}_{\mathrm{SH}}$ UNITS}

With the control issues of the $\mathrm{CC}$ flow in mind, selection of a control strategy for the $\mathrm{APF}_{\mathrm{sh}}$ units should be made. Different control strategies for parallel operation of multiple APF units were reviewed [1,2]. In general, control can be based on active current sharing where the compensating power/current can be divided equally or up to the compensating capacity of the APF units. Another prominent control is droop control where information exchange between the $\mathrm{APF}_{\mathrm{sh}}$ units is not required. For simplicity, a current sharing (power splitting) method based on hysteresis current control has been chosen for the remainder of the analysis.

\section{Simulation StUdy}

In depth information on parallel operation of multiple $\mathrm{APF}_{\text {sh }}$ based on hysteresis current controller is not yet available, especially in the case of ZSCC flow. Therefore, in the present work, the objective is to reduce the ZSCC flow based on the design parameter selection. Two units of $\mathrm{APF}_{\mathrm{sh}}$ have been modelled here to operate in power sharing mode. In terms of sharing following proportions have been chosen:

(A) $I_{A P F s h 1}=I_{A P F s h 2}=0.5 * I_{l q h-\max }$ and $I_{l q h-\max }=$ $100 A$; each $\mathrm{APF}_{\text {sh }}$ compensates half of the load reactive and harmonic components.

(B) $I_{A P F s h 1}=0.6 * I_{l q h-\max } ; I_{A P F s h 2}=0.4 * I_{l q h-\max }$; and $I_{\text {lqh-max }}=100 \mathrm{~A}$

(C) $I_{A P F s h 1}=0.6 * I_{l q h-\max } ; I_{A P F s h 2}=0.4 * I_{l q h-\max } ;$ and $I_{\text {lqh-max }}=200 \mathrm{~A}$

In the case of a hysteresis current control based $\mathrm{APF}_{\mathrm{sh}}$, according to the selection of design parameters described in $[12,13]$ and the control issues of CC flow, the CC flow can be reduced by the proper selection of the design components including $f_{s w}, L_{s h}, h$ and $V_{d c}$. As the $V_{d c}$ is fixed, variation of other components has been made here to analyze the reduction of $\mathrm{CC}$ flow. Results and discussion are given below.

Table 1 shows the parameters that have been considered for the proportion (A), as mentioned above. Corresponding results have been given in Fig 3 and discussed below.

Fig 3 shows the performance study of the two $\mathrm{APF}_{\text {sh }}$ units in power sharing mode for the cases (A1 - A5) where each of the units compensates half of the load reactive and harmonic components. For the cases (A1-A3), the switching frequency of both units was equal and the variations have been made for $L_{s h}$ and $h$. Cases A1 and A2 show that the possible CC flow can be zero when $L_{s h 1}=L_{s h 2}$ and $h 1=h 2$, i.e, both the $\mathrm{APF}_{\mathrm{sh}}$ units are identical. Although the rating and $f_{s w}$ of each unit are the same, ZSCC can flow as shown in case A3. This happens due to the difference in design parameters $L_{s h}$ and $h$. Cases A4 and A5 shows the results for different $f_{s w}, L_{s h}$ and $h$. For both the cases, ZSCC flows. A comparison with A3, A4 and A5, A5 shows better results in 
the reduction of ZSCC flow. It is due to the higher values of $L_{s h}$ and lower values of $h$, though the $f_{s w}$ is different.

TABLE1

\begin{tabular}{|c|c|c|c|c|}
\hline $\mathrm{A}: I_{A P F}$ & $=I_{A P F S h}$ & $0.5 * I_{l q h-m}$ & $\mathrm{ND}_{l q h-\max }$ & $100 A$ \\
\hline $\begin{array}{l}\text { Frequency } \\
(\mathrm{kHz})\end{array}$ & Cases & $\begin{array}{c}L_{s h 1} / L_{s h 2} \\
(\mathrm{mH})\end{array}$ & $\begin{array}{c}h 1 / h 2 \\
\text { (A) }\end{array}$ & $\begin{array}{c}T H D @ I_{p c c} \\
(\%)\end{array}$ \\
\hline \multirow{3}{*}{$\begin{array}{l}f_{s w 1}=17.3 \\
f_{s w 2}=17.3\end{array}$} & A1 & $0.625 / 0.625$ & $5 / 5$ & 2.57 \\
\hline & A2 & $1.25 / 1.25$ & $2.5 / 2.5$ & 2.02 \\
\hline & A3 & $1.25 / 0.625$ & $2.5 / 5$ & 1.74 \\
\hline \multirow{2}{*}{$\begin{array}{l}f_{s w 1}=17.3 \\
f_{s w 2}=11.6\end{array}$} & A4 & $1.25 / 1.25$ & $2.5 / 3.75$ & 1.67 \\
\hline & A5 & $1.25 / 1.875$ & $2.5 / 2.5$ & 2.35 \\
\hline \multirow{3}{*}{$\begin{array}{l}f_{s w 1}=13.0 \\
f_{s w 2}=11.6\end{array}$} & A6 & $1.67 / 0.625$ & $2.5 / 5$ & 2.88 \\
\hline & A7 & $1.67 / 1.25$ & $2.5 / 3.75$ & 2.82 \\
\hline & A8 & $1.67 / 1.875$ & $2.5 / 2.5$ & 3.76 \\
\hline
\end{tabular}

Tables 2 and 3 show the parameters for the cases B and C where the sharing proportion is different than that for A. For both the cases, values of $L_{s h}$ are kept low whereas the values for $h$ are high. In both cases, $f_{s w}$ are the same. And the same components has been chosen for $\mathrm{C}$ where the compensating current is two times higher than that of case $\mathrm{B}$.

Fig 4 shows the performances for the cases of $\mathrm{C}$ and $\mathrm{D}$ in terms of ZSCC flow. In both cases, ZSCC flow is the same even though for case $\mathrm{D}, \mathrm{APF}_{\mathrm{sh}}$ units are compensating higher current than that of $\mathrm{C}$. These results indicate that the ZSCC flow does not depends on the amount of compensating current. These ZSCC flows are higher than that for A and this is due to the lower values of $L_{s h}$.

TABLE 2

\begin{tabular}{|} 
C: $I_{A P F s h 1}=0.6 * I_{l q h-\max } ; I_{A P F s h 2}=0.4 * I_{l q h-\max } ; I_{l q h-\max }=100 \mathrm{~A}$ \\
\hline $\begin{array}{c}\text { Frequency } \\
(\mathrm{kHz})\end{array}$ & Cases & $\begin{array}{c}L_{s h 1} / L_{\text {sh } 2} \\
(\mathrm{mH})\end{array}$ & $\begin{array}{c}H 1 / h 2 \\
(\mathrm{~A})\end{array}$ & $\begin{array}{c}\text { THD@ } I_{p c c} \\
(\%)\end{array}$ \\
\hline$f_{s w 1}=17.3$ & $\mathrm{C} 1$ & $0.625 / 0.625$ & $5 / 5$ & 2.65 \\
$f_{s w 2}=17.3$ & & & & \\
\hline
\end{tabular}

TABLE 3

$\mathrm{D}: I_{A P F \operatorname{sh} 1}=0.6 * I_{l q h-\max } ; I_{A P F \operatorname{sh} 2}=0.4 * I_{l q h-\max } ; I_{l q h-\max }=200 \mathrm{~A}$

\begin{tabular}{|c|l|c|c|c|}
\hline $\begin{array}{c}\text { Frequency } \\
(\mathrm{kHz})\end{array}$ & Cases & $\begin{array}{c}L_{s h 1} / L_{s h 2} \\
(\mathrm{mH})\end{array}$ & $\begin{array}{c}H 1 / h 2 \\
(\mathrm{~A})\end{array}$ & $\begin{array}{c}\text { THD@ } I_{p c c} \\
(\%)\end{array}$ \\
\hline$f_{s w 1}=17.3$ & $\mathrm{D} 1$ & $0.625 / 0.625$ & $5 / 5$ & 2.12 \\
$f_{s w 2}=17.3$ & & & & \\
\hline
\end{tabular}

Finally, a comparison has been made for the ZSCC between the (A3 - A5) and (A6 - A8) cases, as shown in Fig 5. For $\mathrm{A} 3$, the $f_{s w}$ is the same for both $\mathrm{APF}_{\text {sh }}$ units, whereas for $\mathrm{A} 4$ and $\mathrm{A} 5$ it is different. But the values of $L_{s h}$ are comparatively higher for A5. Therefore, within A3 to A5, the ZSCC flow is comparatively lower in the case of A5, as shown in Fig 5(a).

For the cases A6 - A 8 , the switching frequency $\left(f_{s w 1}\right)$ of $\mathrm{APF}_{\mathrm{sh} 1}$ is reduced and therefore the value of $L_{s h}$ increases. At the same time, the frequency difference between $\mathrm{APF}_{\mathrm{sh}}$ units are also reduced. The performance of the $\mathrm{APF}_{\mathrm{sh}}$ units in terms of ZSCC flow for these cases is reflected in Fig 5(b). This shows that ZSCC flow can further be reduced by reducing the $f_{s w}$ (to increase the value of $L_{s h}$ ) and the difference between the $f_{s w}$ of the $\mathrm{APF}_{\text {sh }}$ units. The reduction of zero sequence harmonics content for the cases (A6 - A8) are also shown in Fig 6 where it shows that the magnitude of zero sequence harmonics is reduced gradually for the cases from A6 to A8. This also confirms the outcome as shown in Fig 5.

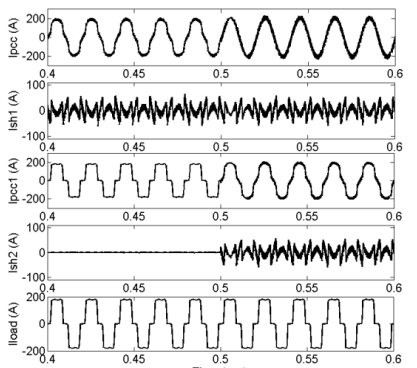
(A1a)

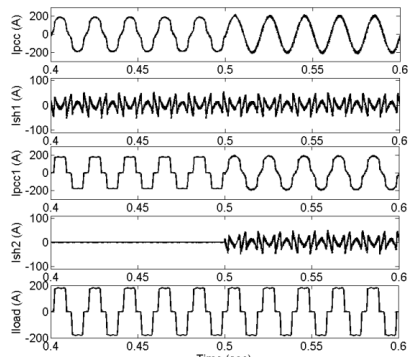
(A2a)

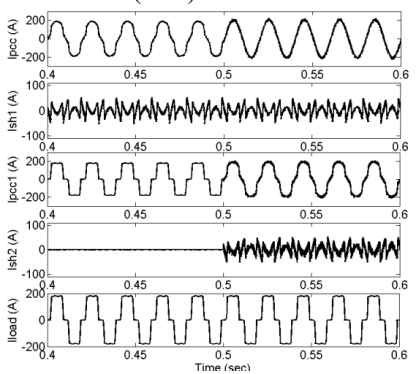
(A3a)

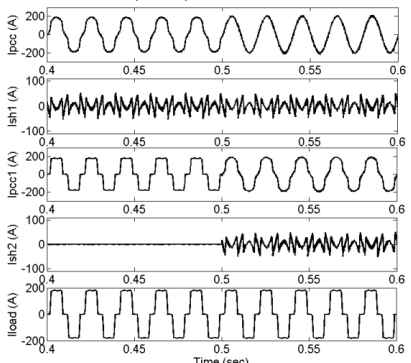
(A4a)

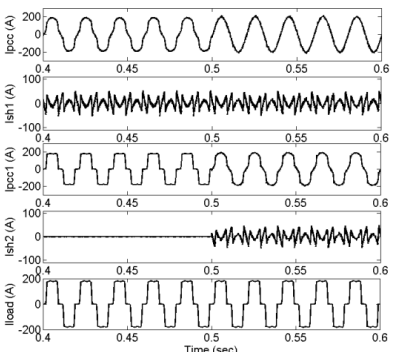

(A5a)

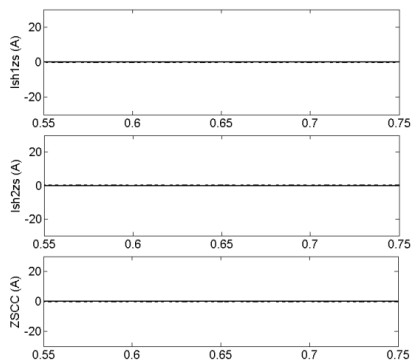

(A1b)

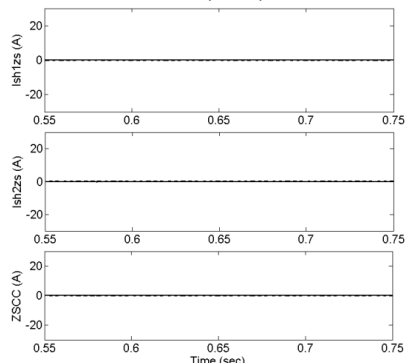

(A2b)

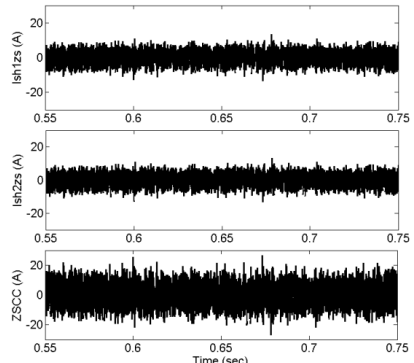

(Aime rsec)

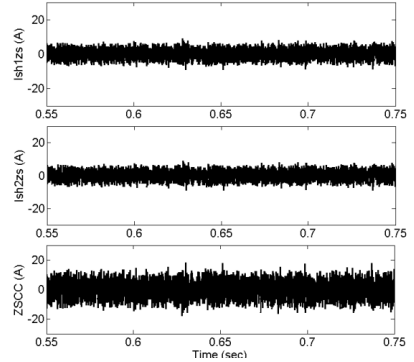

(Aime (sec)

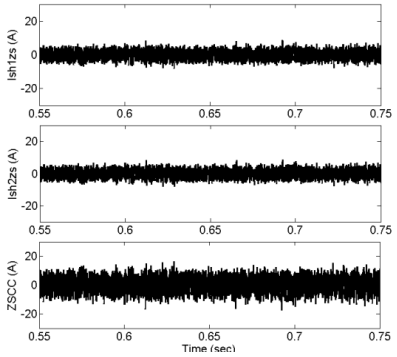

(A5b)
Fig 3: Performance of $\mathrm{APF}_{\mathrm{sh}}$ for the cases $(\mathrm{A} 1$ - $\mathrm{A} 5)$ and the corresponding CC flow 


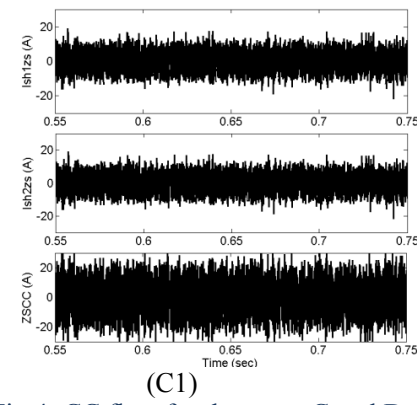

Fig 4: CC flow for the cases C and D

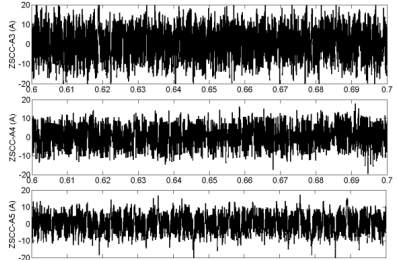

(a)
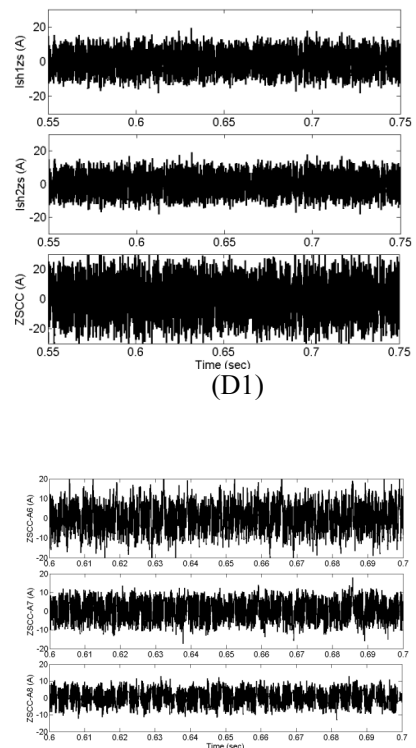

(b)
Fig 5: ZSCC comparison between the cases for (a) A3, A4, A5 and for (b) A6, A7, A8

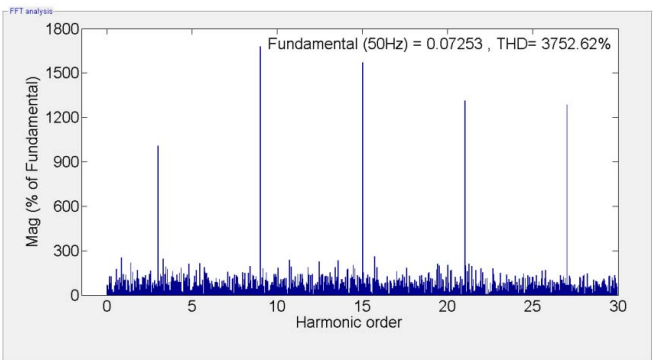

(a)

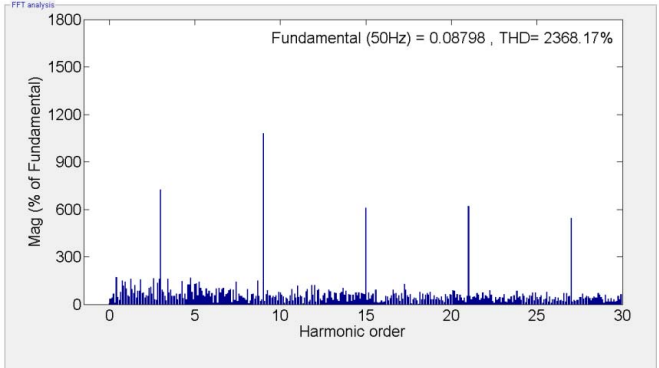

(b)

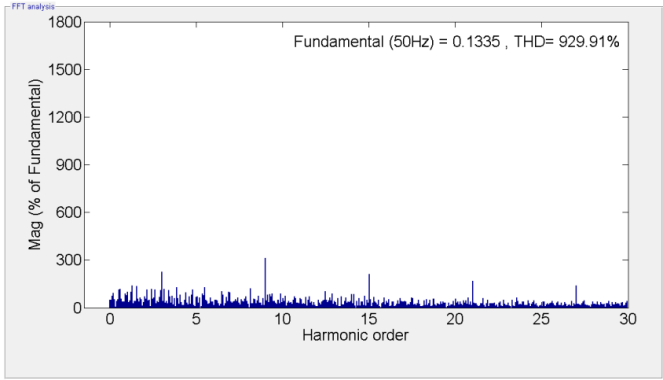

(c)

Fig 6: FFT analysis for the cases (a) A6, (b) A7 and (c) A8.

But it also has to be kept in mind that increasing $L_{s h}$ could increase the THD at the PCC, as given in Table 1. Therefore, in terms of design criteria for the selection of $\mathrm{APF}_{\mathrm{sh}}$ units to place in multiple units with common DC link system, one should consider the higher values of $L_{s h}$ and lower the difference between $f_{s w}$ of the $\mathrm{APF}_{\text {sh }}$ units with care about THD.

\section{REAL-TIME PERFORMANCE STUDY}

With the advancement of technology, real-time performance of any system can be observed using a real-time simulator. Instead of developing the complete actual system at full capacity, either the controller/system can be modelled in software or can be built in hardware or can be a combination of both. In real-time simulation, the accuracy of the computations depends upon the precise dynamic representation of the system and the processing time to produce the results [14].

An electrical power system including 2 units of $\mathrm{APF}_{\mathrm{sh}}$ has been modelled in MATLAB using RT-LAB (real-time simulation) tools to observe the performance in the real-time environment. The system is then tested in SIL (Software-inLoop; both the controller and the plant can be simulated in real-time in the same simulator) with the hardware synchronization mode which is similar to hardware-in-loop (HIL) test. Fig 7 shows the real-time simulation structure in a SIL configuration used to develop the real-time environment by OPAL-RT. With the combination of MATLAB SPS (Sim Power System) from MATHWORKS and the RT-LAB toolbox from OPAL-RT, the real-time model of the power system and controller is developed for the real-time simulator.

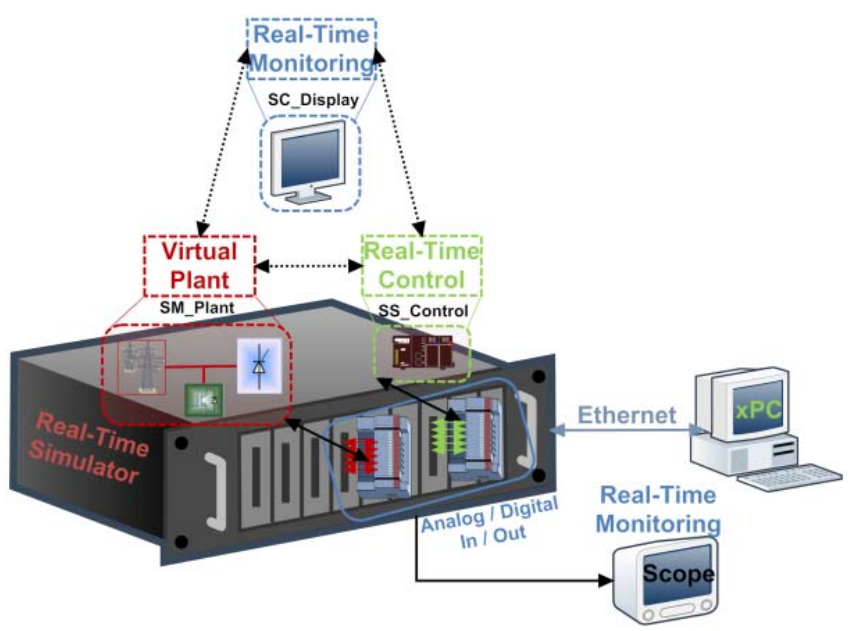

Fig 7: Real-time simulation structure in SIL configuration with hardware synchronization mode

Fig 8 shows the ZSCC flow for these (A6 - A8) cases and it clearly depicts the gradual reduction of ZSCC from A6 to A8. It is also clear from Fig 8 that a considerable amount of ZSCC can be reduced by proper selection of design parameters for the $\mathrm{APF}_{\text {sh }}$ units to operate in load sharing mode. Thus it validates the simulation and ZSCC flow study. 


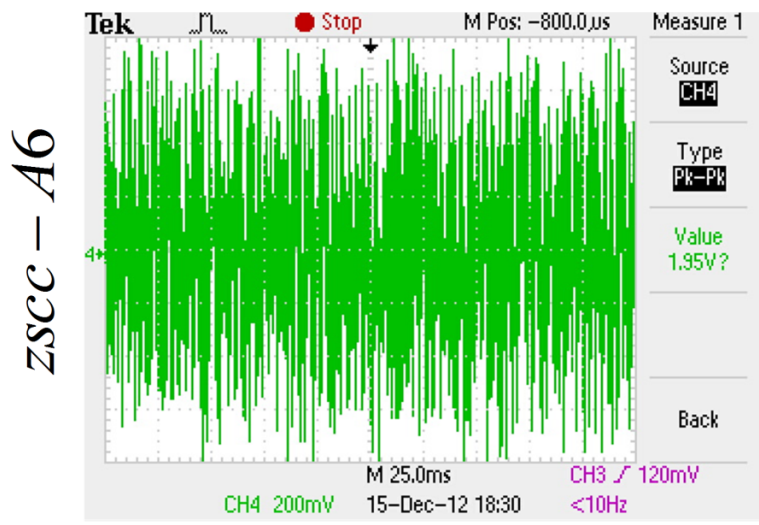

(a)

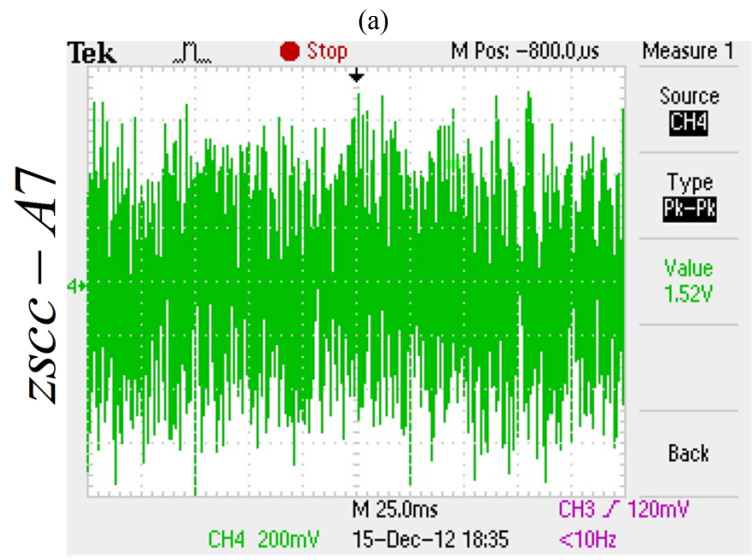

(b)

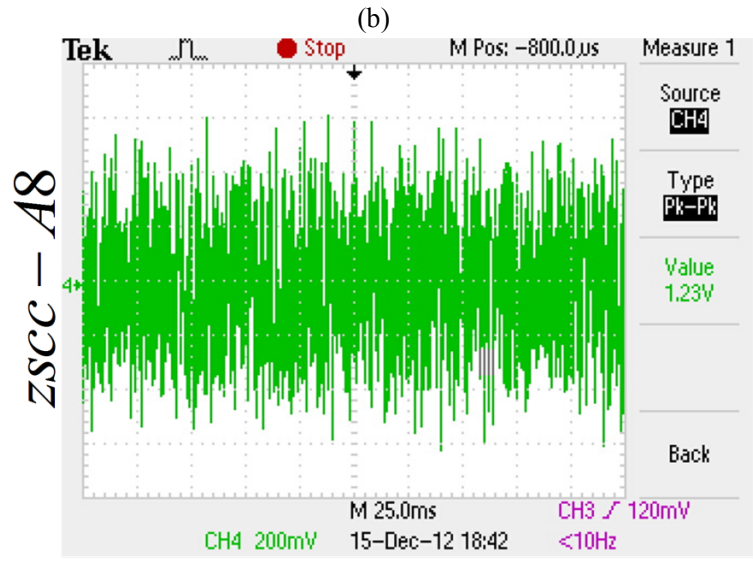

(c)

Fig 8: ZSCC flow for the cases of (a) A6, (b) A7 and (c) A8

\section{CONCLUSION}

In the case of a hysteresis current controller based multiple $\mathrm{APF}_{\text {sh }}$ units in load sharing mode, the ZSCC flow control is not yet achieved. One of the difficulties of this $\mathrm{CC}$ flow control or reduction is the variable switching frequency of the $\mathrm{APF}_{\mathrm{sh}}$ units. In this paper, the simulation and real time study show the impact of design parameter selection for the $\mathrm{APF}_{\mathrm{sh}}$ units on the reduction of ZSCC. By proper selection of design parameters, this $\mathrm{CC}$ flow can be reduced in an acceptable level. It can be concluded that engineer should consider the higher values of $L_{s h}$ and lower the difference between $f_{s w}$ of the $\mathrm{APF}_{\mathrm{sh}}$ units with care about the THD limit.

\section{REFERENCES}

[1] S. K. Khadem, M. Basu and M. F. Conlon, "A review of parallel operation of active power filters in the distributed generation system," Power Electronics and Applications (EPE 2011), Proceedings of the 2011-14th European Conference on , vol., no., pp.1-10, Aug. 30 2011Sept. 12011

[2] S. K. Khadem, M. Basu and M. F. Conlon, "Parallel Operation of Inverters and Active Power Filters in Distributed Generation System - a Review", Renewable and Sustainable Energy Reviews, vol.15, 2011, pp. $5155-5168$

[3] H Akagi and K Nabae, Control strategy of active power filters using multiple voltage source PWM converters, IEEE Trans. Ind. Appl. 1(3) (1985), pp. 460-466

[4] L Asiminoaei, E Aeloiza, J Kim, P H Enjeti, F Blaabjerg, L Moran, S Sul, Parallel Interleaved Inverters for Reactive Power and Harmonic Compensation, PESC, (2006), pp.1-7

[5] L Asiminoaei, C. Lascu, Performance Improvement of Shunt Active Power Filter With Dual Parallel Topology, IEEE Trans Power Electronics 22(1) (2007), pp. 247-259

[6] Z Ye, D Boroyevich, J Y Choi and F C Lee, Control of circulating current in parallel three-phase boost rectifiers, IEEE APEC (2000), pp. 506-512.

[7] Chen, T P, Circulating zero-sequence current control of parallel threephase inverters, Electric Power Applications, vol.153, no.2, pp. 282288,2006

[8] C T Pan and Y H Liao, Modeling and coordinate control of circulating currents in parallel three-phase boost rectifiers, IEEE Trans. Ind. Electron. 54(2) (2007), pp. 825-838

[9] Ching-Tsai Pan, Yi-Hung Liao, Modeling and Coordinate Control of Circulating Currents in Parallel Three-Phase Boost Rectifiers, IEEE Trans Ind Elec, vol.54, no.2, pp.825-838, 2007

[10] T P Chen, Zero-Sequence Circulating Current Reduction Method for Parallel HEPWM Inverters Between AC Bus and DC Bus, IEEE Trans IE, vol.59(1), pp.290-300, 2012

[11] L Asiminoaei, E Aeloiza, P Enjeti, F Blaabjerg, Shunt Active-PowerFilter Topology Based on Parallel Interleaved Inverters, IEEE Trans IE, vol.55(3), pp.1175-1189, 2008

[12] S K Khadem, M Basu and M F Conlon, Harmonic Power Compensation Capacity of Shunt APF and its Relationship to Design Parameters, IET Power Electronics, 2013 in press.

[13] M K Mishra, K Karthikeyan, An investigation on design and switching dynamics of voltage source inverter to compensate unbalanced and non-linear loads, IEEE Trans. Ind Electron, Vol. 56 (8), 2009, pp 2802 $-2810$

[14] P Venne, J N Paquin, J Bélanger, The What, Where and Why of RealTime Simulation, PES general meeting, 2010, pp. 37 - 49 